\title{
Naturalization of alien plants in China
}

\author{
Hua Jiang • Qiang Fan · Jin-Tian Li $\cdot$ Shi Shi $\cdot$ Shao-Peng Li $\cdot$ \\ Wen-Bo Liao $\cdot$ Wen-Sheng Shu
}

Received: 31 January 2011/Accepted: 1 April 2011/Published online: 12 April 2011

(C) The Author(s) 2011. This article is published with open access at Springerlink.com

\begin{abstract}
Naturalization (the establishment of a self-sustaining population for at least a decade) is a fundamental precondition for plant invasion and so compiling a complete inventory of naturalized alien species is necessary for predicting and hence preventing such invasion. However, nationwide information on naturalized plants in China is still lacking. We compiled a nationwide list of the naturalized plant species of China, based on various literature reports. The list comprised a total of 861 naturalized plant species belonging to 110 families and 465 genera. The three most dominant families were Compositae, Poaceae, and Leguminosae, accounting for 16, 13 and 12\% of naturalized plants, respectively. Among genera, Euphorbia and Solanum had the most naturalized species, followed by Ipomoea, Amaranthus, Oenothera, and Trifolium. Over half of all aliens were of American origin (52\%), followed by those with European (14\%) and Asian (13\%) origins. Annuals and perennial herbs were prevalent among naturalized species; comparison to other studies suggests however that the invasive potential is higher among plants with longer life cycles than those of annuals. The taxonomic pattern of plant naturalization in China is similar to patterns worldwide. However, the low proportion of naturalized plants within the Chinese flora overall suggests that the potential for plant invasions in China may be high. Therefore, greater attention should be focused on naturalization of alien plants in China, especially concerning species of dominant families or genera, and those with a perennial life cycle.
\end{abstract}

Keywords Invasion $\cdot$ Life form $\cdot$ Naturalization $\cdot$ Taxonomic pattern

Electronic supplementary material The online version of this article (doi:10.1007/s10531-011-0044-x) contains supplementary material, which is available to authorized users.

H. Jiang · Q. Fan · J.-T. Li · S. Shi · S.-P. Li · W.-B. Liao · W.-S. Shu (ه)

State Key Laboratory of Biocontrol and Guangdong Provincial Key Laboratory of Plant Resource, School of Life Sciences, Sun Yat-Sen University, Guangzhou 510275, People's Republic of China e-mail: shuws@mail.sysu.edu.cn 


\section{Introduction}

Biological invasions by alien species are widely recognized as a significant component of human-caused global environmental change. Invasive alien plant species may profoundly alter ecosystem structure, resulting in significant losses in the economy, and in the biological diversity and function of invaded ecosystems, and thus are of great concern to both ecologists and economists (Elton 1958; Lonsdale 1999; Pimentel et al. 2000; Meyerson and Mooney 2007).

The stages in the invasion process of alien plants are complex and the processes represent a continuum. Naturalization is a fundamental precondition for plant invasion. The naturalization process of alien plants introduced intentionally or unintentionally occurs when abiotic and biotic barriers to survival and reproduction are overcome. Naturalized plants may become invasive in new habitats only when they produce adequate reproductive off-spring (Richardson et al. 2000; Pyšek et al. 2004). Compilation of comprehensive lists of the naturalized species list for a given country, and comparative studies of naturalized floras in different regions, have proved to be a useful approach to understanding taxonomic patterns of plant invasion (Pyšek et al. 2004; Khuroo et al. 2007) and are the first steps towards developing management strategies for invasive species.

China is the world's third largest country with a total area of 9.6 million $\mathrm{km}^{2}$ and encompassing a wide range of habitats and environmental conditions (Xie et al. 2001). The estimated annual economic loss in China due to invasive alien species may amount to US\$ 15 billion ( $\mathrm{Xu}$ et al. 2006a). The problem of invasive alien species in China has been discussed by a number of authors with emphasis on harmful invasive plants (e.g., Ding and Wang 1998; Qiang and Cao 2000; Li and Xie 2002; Liu et al. 2005; Xu et al. 2006b; Liu et al. 2006; Ding et al. 2008; Weber et al. 2008; Huang et al. 2009; Feng and Zhu 2010). A number of regional lists of naturalized plants have been compiled, e.g., for Shandong (Wu et al. 2006), Guangzhou (Yan et al. 2007), Hong Kong (Corlett 1992, Ng and Corlett 2002), Macau (Wang et al. 2004), and Taiwan (Wu et al. 2004a, b, 2010b). Most recently, a list of 420 naturalized plant species occurring in mainland China was compiled by $\mathrm{Wu}$ et al. (2010a). This provided an important advance, while nationwide documentation of naturalized plants in China is still lacking.

Considering that the naturalized floras of many countries or continents have been well documented, e.g., Europe (Weber 1997; Lambdon et al. 2008), Mexico (Villaseñor and Espinosa-Garcia 2004), Kashmir Himalaya (Khuroo et al. 2007), North Africa (Vilà et al. 1999), Austria (Rabitsch and Essl 2006), and Singapore (Corlett 1988), comprehensive documentation of naturalized alien species in China therefore stands to provide an important data set for comparative studies of alien floras, and offer new insights to our understanding of global patterns of plant invasions. In this light, our main objective in the present study is to compile a database of naturalized plants in China. Based on this compilation, we then address the four specific questions: (1) What is the current prevalence of naturalized plants in China? (2) Is there a taxonomic pattern? (3) Where did these species originate? and (4) Are there life form and habit characters associated with plant invasion? We hope that this effort will contribute towards offering insightful perspectives and information for further regional or global studies of plant invasion. 


\section{Methods}

\section{Definition}

In both English and Chinese literature, the concepts associated with terms "invasion", "naturalization", "alien" species, and "exotic" species are often confused. This confusion may lead to over- or under-estimation of the real level of invasion or naturalization in a given region, and is also an obstacle for comparative research on the spread of alien plants around the world. For the purpose of this study, the terms used in the present paper are defined here strictly according to concepts suggested by Richardson et al. (2000) and Pyšek et al. (2004). Alien plants in China are all those which have their origins outside China and were introduced intentionally or accidentally. Naturalized plants are alien plants that sustain self-replacing populations for at least 10 years without direct intervention by people and which are capable of independent growth. Invasive plants are a subset of naturalized plants which produce reproductive offspring, and have spread beyond their area of introduction. The term "invasive" used here is defined without any inference to environmental or economic impact.

Catalogue of naturalized species

We compiled a nationwide list of the current naturalized flora of China (Appendix S1), based on the list of 233 invasive plant species in China released by the Institute of Plant Protection (IPP), Chinese Academy of Agricultural Sciences (CAAS) (2008) (http://www. agripests.cn), regional lists of invasive and naturalized plant species, and various other publications released before October 2010 (references listed in Appendix S1). Only plant species with foreign origins were considered as naturalized, and so a number of species that have been considered by some authors as naturalized in some regions of China but native to other regions of the country were not included. For example, many species native to south China were identified as naturalized and invasive species in Hong Kong or Taiwan; we deleted these in the present list. The synonyms of some species were corrected to their accepted names according to the 'Catalogue of Life, China, 2009 Annual Checklist' ( http://data.sp2000.cn/2009_cnnode_c/search.php), or the 'Flora of China' (1959-2002) (Editorial Board for Flora of China). The naturalized status, origins, life forms of these species were extracted from these references, and were further corrected one by one following the 'Flora of China' or various provincial floras.

\section{Data analysis}

We calculated the number and proportions of naturalized species per family and genus in China and the world; we further compared the ratios with equivalent global patterns using linear correlation analysis. We also calculated the proportions of species in each category of origin, life form. Because information on the native distribution of species provided in different references is not always consistent, we grouped species by broad categories, i.e., "Africa", "America", "Asia", "Europe" and "Oceania". If a species occurred in more than one area, we placed it in the one where it occurred most frequently; meanwhile, the details on species' distributions are presented in Appendix S1. The proportion of climbing plants (vines and lianas) in the total naturalized flora was also analyzed because these are often the most harmful invasive plants in south China (Hu et al. 2010). 


\section{Results}

Taxonomic diversity

A total of 861 naturalized plant species belonging to 110 families and 465 genera were recorded. They represent about $2.3 \%$ of the approximately 37,000 vascular plant flora of China (Catalogue of Life, China, 2009 Annual Checklist; Table 1; Appendix S1). Among these species, $79 \%$ (681) were dicotyledons, $20 \%$ (168) were monocotyledons, nine species were pteridophytes and three were gymnosperms. Three families, Compositae, Poaceae, and Leguminosae, have more than 100 naturalized species in China and account for 16, 13 and $12 \%$ of the total naturalized plants in the country, respectively (Table 2, Appendix S2). Another five families including Solanaceae, Cruciferae, Euphorbiaceae, Amaranthaceae and Convolvulaceae had more than 26 naturalized plants $(>3 \%$ of the total naturalized species in China) each, while about $42 \%$ of the families (46) contributed only one species to the naturalized flora. This taxonomic pattern of plant invasion in China is highly similar (Fig. 1, $r=0.79, P<0.0001$ ) to the worldwide pattern summarized by Pyšek (1998).

Six genera had more than 10 naturalized species: Euphorbia (Euphorbiaceae) and Solanum (Solanaceae) have the most naturalized species (18), followed by Ipomoea (Convolvulaceae), Amaranthus (Amaranthaceae), Oenothera (Onagraceae) and Trifolium (Leguminosae) (Table 3). Each of another 22 important naturalized genera hold more than 5 naturalized species, while about $50 \%$ of the genera are represented by a single naturalized species (Appendix S1).

Geographic origin

More than half of the naturalized alien plant species of China were of American origins (52\%), followed by those with European (14\%) and Asian (13\%) origins. Africa was also an important origin of the naturalized plant species (74 species, 9\%), while less than 20 naturalized plant species from the Mediterranean, the Pantropics, and Oceania, each of them accounted for $<2 \%$ of the total naturalized plant species in China (Fig. 2). The information on the native distributions of about $2 \%$ of the naturalized species was not consistent, or the origins were unclear.

\section{Life form}

The life forms of the naturalized plants were characterized by a prevalence of annuals and perennial herbs (Fig. 3). Herbs accounted for about 82\% (including vines), while woody

Table 1 Taxonomic composition of the naturalized flora of China

\begin{tabular}{lcccc}
\hline Plant group & $\begin{array}{l}\text { Number } \\
\text { of families }\end{array}$ & $\begin{array}{l}\text { Number } \\
\text { of genus }\end{array}$ & $\begin{array}{l}\text { Number } \\
\text { of species }\end{array}$ & $\begin{array}{l}\text { \% of (species } \\
\text { pool of China) }\end{array}$ \\
\hline Dicotyledons & 83 & 368 & 681 & $2.5(27,752)$ \\
Monocotyledons & 20 & 90 & 168 & $2.5(6,624)$ \\
Gymnosperms & 2 & 2 & 3 & $0.9(316)$ \\
Pteridophytes & 5 & 5 & 9 & $0.4(2,433)$ \\
Total & 110 & 465 & 861 & $2.3(37,125)$ \\
\hline
\end{tabular}

The species pool of China based on Catalogue of Life, China, 2009 Annual Checklist 
Table 2 Taxonomic diversity in the families with more than five naturalized plant species in China

China (\%) represents the number of naturalized species in each family in China: the total number of species in each family in China. Similarly, world (\%) represents the number of naturalized species in each family in China: the total number of species in each family worldwide (Mabberley 1997)

\begin{tabular}{lcccl}
\hline Family & Species & Genera & China $(\%)$ & World $(\%)$ \\
\hline Compositae & 134 & 76 & 5.2 & 0.6 \\
Poaceae & 109 & 50 & 5.1 & 1.1 \\
Leguminosae & 106 & 47 & 5.3 & 0.6 \\
Solanaceae & 38 & 11 & 32 & 1.3 \\
Cruciferae & 35 & 18 & 7.4 & 1.1 \\
Euphorbiaceae & 29 & 9 & 6.8 & 0.4 \\
Amaranthaceae & 27 & 7 & 49 & 3.6 \\
Convolvulaceae & 26 & 7 & 17 & 1.6 \\
Onagraceae & 18 & 4 & 24 & 2.8 \\
Rubiaceae & 16 & 11 & 2.0 & 0.2 \\
Scrophulariaceae & 16 & 10 & 1.9 & 0.3 \\
Malvaceae & 14 & 9 & 12 & 0.8 \\
Caryophyllaceae & 13 & 9 & 2.7 & 0.6 \\
Labitae & 13 & 8 & 1.3 & 0.2 \\
Acanthaceae & 11 & 8 & 3.5 & 0.3 \\
Cactaceae & 9 & 5 & 100 & 0.6 \\
Cyperaceae & 9 & 5 & 0.9 & 0.2 \\
Umbelliferae & 9 & 8 & 1.3 & 0.3 \\
Verbenaceae & 9 & 6 & 4.0 & 0.9 \\
Apocynaceae & 8 & 7 & 5.4 & 0.4 \\
Agavaceae & 7 & 1 & 100 & 3.3 \\
Cucurbitaceae & 7 & 6 & 3.4 & 0.9 \\
Polygonaceae & 7 & 6 & 2.5 & 0.6 \\
Amaryllidaceae & 6 & 4 & 14 & 0.8 \\
Araceae & 6 & 5 & 2.4 & 0.2 \\
Boraginaceae & 6 & 4 & 1.8 & 0.3 \\
Chenopodiaceae & 6 & 2 & 2.9 & 0.5 \\
Iridaceae & 6 & 3 & 8.1 & 0.4 \\
Crassulaceae & 5 & 4 & 1.8 & 0.5 \\
Liliaceae & 5 & 4 & 0.6 & 0.1 \\
Lythraceae & 5 & 4 & 10 & 0.8 \\
Passifloraceae & 5 & 1 & 20 & 0.9 \\
Plantaginaceae & 5 & 1 & 19 & 1.8 \\
Ranunculaceae & 5 & 1 & 0.4 & 0.2 \\
Zingiberaceae & 5 & 5 & 2.1 & 0.5 \\
\hline & & & & \\
\hline
\end{tabular}

plants (shrub and tree) comprised only $13 \%$ of the total naturalized plants, with semishrubs (herb/shrub) accounting for the remaining $4 \%$. The total number of climbers amounted to $8 \%$ of the naturalized plants, with $6 \%$ veins and $2 \%$ lianas.

We compared the proportion of naturalized annual: perennial species in our dataset to the equivalent proportion in the datasets on invasive plant species (compiled by Weber et al. 2008) and on "major" invasive plant species (compiled by Liu et al. 2006). We found that the proportion of annual plant species decreased evidently when moving from naturalized through invasive to "major" invasive (Fig. 4). 


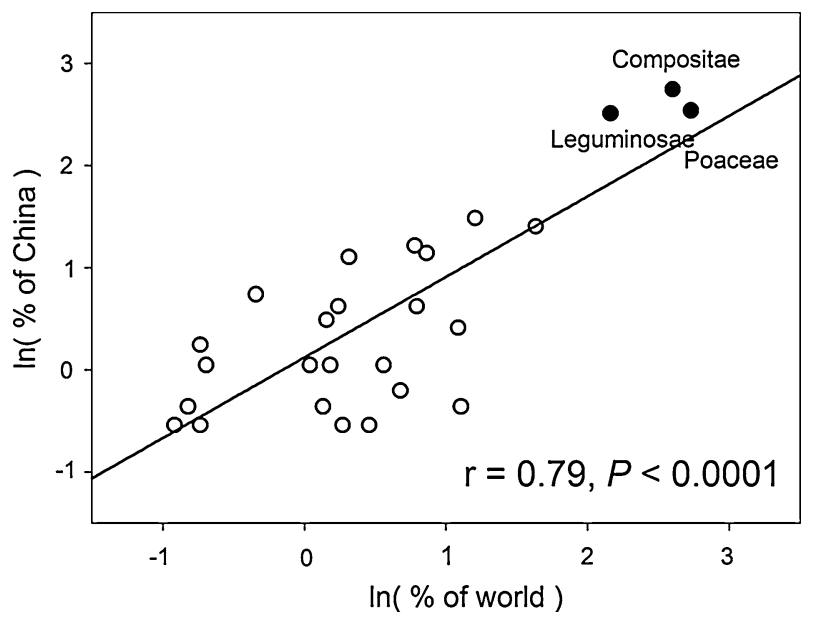

Fig. 1 The taxonomic pattern of plant naturalization in China compared to patterns worldwide. The proportion of naturalized plant species per family (for families with more than five naturalized plant species): total naturalized species compared between China and the average of 26 naturalized floras for elsewhere in the world determined by Pyšek (1998)

\section{Discussion}

Most previous studies of alien species in China have focused on spatial patterns, species composition and risk assessment of "harmful invasive plants". However, the number of invasive plants in China reported in previous publications has varied widely, likely due to varying taxonomies, varying definitions of "invasive" and to incremental increases in knowledge. For example, Ding and Wang (1998) reported 58 invasive plants of China; 80 (Xiang et al. 2002); 90 (Li and Xie 2002), 108 (Qiang and Cao 2000), 126 (Liu et al. 2006), 188 (Xu et al. 2006b), and 270 (Weber et al. 2008). Weber and Li (2008) have suggested that a research priority for efficient invasive species management program in China is therefore to assemble standard information on the country's naturalized species.

In the present study, the total number of recorded naturalized plant species was more than twice as many as that reported by Wu et al. (2010a). This increase in the total number of naturalized plants is likely due to a combination: (1) nationwide coverage (including not only mainland China, but also Hainan, Hong Kong, Macao, and Taiwan); (2) compilation of further relevant documents and literatures, especially the recently published regional floras and naturalized literatures; and (3) strict definition of "naturalized", without any inference to environmental or economic impact. Nevertheless, the total number and the proportion of naturalized plants to the whole flora in China are still relatively low compared with other regions. For example, 1,780 naturalized alien plant species have been recorded in Europe (Lambdon et al. 2008), accounting for about 15\% of the continent's flora. The proportions of naturalized plant species in other northern-hemispheric regions are even higher, e.g. Ontario (Canada) 28\% (Morton and Venn 1990), and California (USA) $18 \%$ (Hickman 1993). Only northern Africa has a similarly low proportion, at $1.8-4.9 \%$ in different regions (Vilà et al. 1999).

Two factors might explain the relatively low proportion of naturalized plants in China. First, very likely, we underestimate the naturalized flora, due to shortfalls in both knowledge and available information. We hope that the present compilation could 
Table 3 The dominant genera (with five or more species) of naturalized species in China
China (\%) represents the number of naturalized species in each genus in China: the total number of species in each genus in China. Similarly, world (\%) represents the number of naturalized species in each genus in China: the total number of species in each genus worldwide (Mabberley 1997)

\begin{tabular}{|c|c|c|c|}
\hline Genera & Species & China $(\%)$ & World $(\%)$ \\
\hline Euphorbia & 18 & 23 & 0.9 \\
\hline Solanum & 18 & 42 & 1.1 \\
\hline Ipomoea & 17 & 50 & 2.6 \\
\hline Amaranthus & 14 & 88 & 23 \\
\hline Oenothera & 12 & 100 & 9.7 \\
\hline Trifolium & 11 & 73 & 4.6 \\
\hline Crotalaria & 8 & 15 & 1.3 \\
\hline Lolium & 8 & 100 & 100 \\
\hline Paspalum & 8 & 44 & 2.4 \\
\hline Agave & 7 & 100 & 7.0 \\
\hline Setaria & 7 & 37 & 4.7 \\
\hline Vicia & 7 & 12 & 5.0 \\
\hline Alternanthera & 6 & 100 & 6.0 \\
\hline Brassica & 6 & 25 & 17 \\
\hline Lepidium & 6 & 38 & 4.3 \\
\hline Senna & 6 & 67 & 1.7 \\
\hline Veronica & 6 & 9.5 & 3.3 \\
\hline Acacia & 5 & 19 & 0.4 \\
\hline Bidens & 5 & 33 & 2.1 \\
\hline Cassia & 5 & 33 & 17 \\
\hline Cyperus & 5 & 9.4 & 1.7 \\
\hline Mimosa & 5 & 100 & 1.0 \\
\hline Opuntia & 5 & 100 & 2.5 \\
\hline Passiflora & 5 & 24 & 1.2 \\
\hline Pennisetum & 5 & 45 & 3.9 \\
\hline Phyllanthus & 5 & 14 & 0.8 \\
\hline Plantago & 5 & 19 & 1.9 \\
\hline Ranunculus & 5 & 3.2 & 0.8 \\
\hline
\end{tabular}

stimulate initiation of compiling checklists of naturalized and invasive species in all provinces of China. Second, it is well recognized that naturalization and invasion of alien plants are greatly correlated with human activities (Meyerson and Mooney 2007). Although plant introductions in China have a long history (Xie et al. 2001), large-scale introduction of species from other continents is a rather recent phenomenon (Weber et al. 2008). It is also well documented that the patterns of plant naturalization/invasion are fundamentally linked with the intensity of international trade/tourism (Thuiller et al. 2005); and the frequency of trade/travel between China and other regions was very low before 1980, which was probably a main reason for the relatively low proportion of naturalized plants in China. However, China is currently undergoing a rapid economic development and increasing international trade, and as a consequence, plant invasions in China have intensified dramatically in recent decades (Lin et al. 2007), and more invasions are supposed to occur in near further (Weber and Li 2008).

The present comprehensive catalogue of naturalized plants in China elucidates the taxonomic pattern of plant invasion in China relative to the rest of the world. The three most prevalent naturalized families in China, Compositae, Poaceae, and Leguminosae, are 


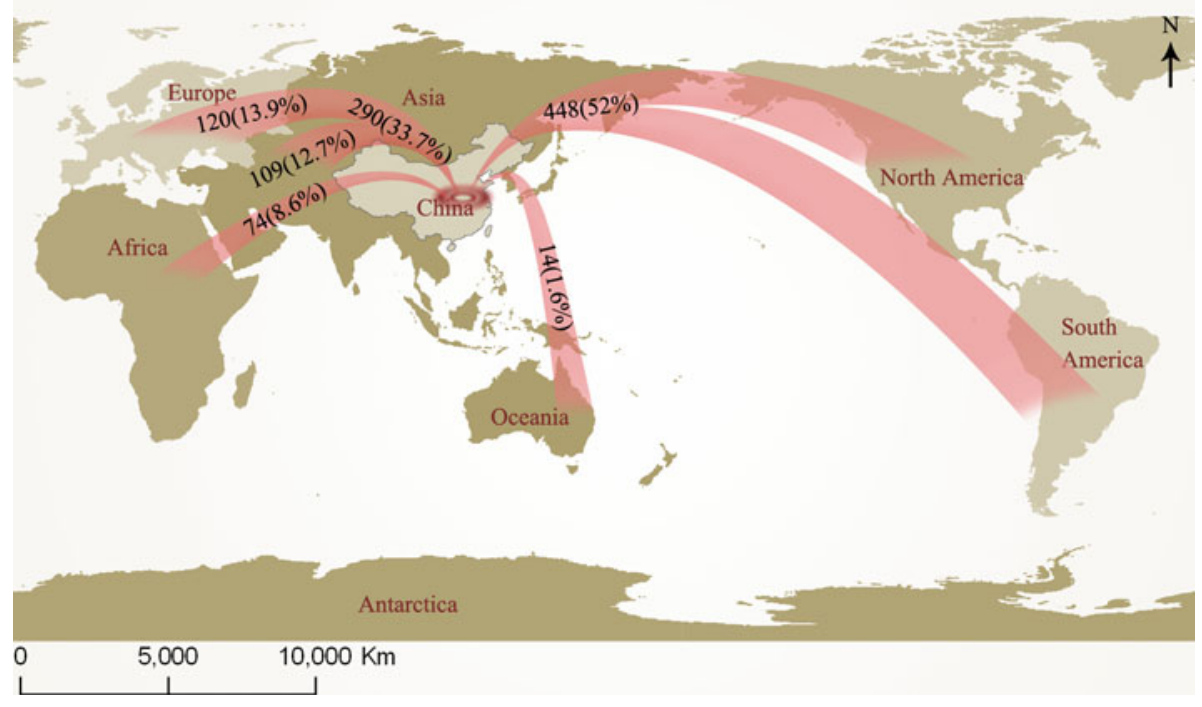

Fig. 2 Geographical origin of the naturalized plant species of China. The $33.7 \%$ Asian and European origins also includes $7.1 \%$ Eurasian and $1.7 \%$ Mediterranean origins. Besides these, Pantropics, Cosmopolitan and uncertain origins accounts for the rest $2,0.7$ and $1.4 \%$, respectively

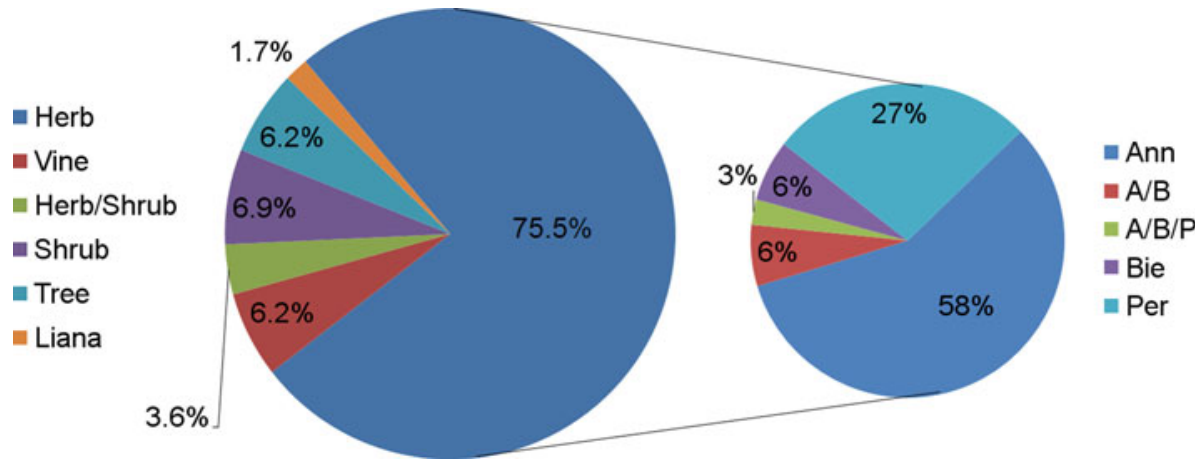

Fig. 3 Life form of the naturalized plant species in China. Left: life form of the naturalized plants; Right: life form of herbs. Ann annual, Bie biennial, Per perennial, $A / B$ annual or biennial, $A / B / P$ annual or biennial or perennial

also major contributors to the alien floras in many other regions of Asia (Corlett 1988; Wu et al. 2004a, b) and of the world (Hickman 1993; Weber and Li 2008). These families are among to the largest families worldwide (Daehler 1998; Douglas et al. 2009), and indeed, global family size has been shown to be a predictor for the number of alien plants in a flora (Hickman 1993; Weber 1997; Zerbe et al. 2004; Lambdon et al. 2008). The other five dominant families were also well represented in alien floras of Asia and of the world (Heywood 1989, 1993; Morton and Venn 1990; Khuroo et al. 2007). Some families, such as Labiatae, Cucurbitaceae, Amaryllidaceae, Araceae, were overrepresented in the naturalized flora of China compared with that for the world (Appendix S2) presumably due to their introduction into China as ornamentals, herbal medicines or vegetables. 


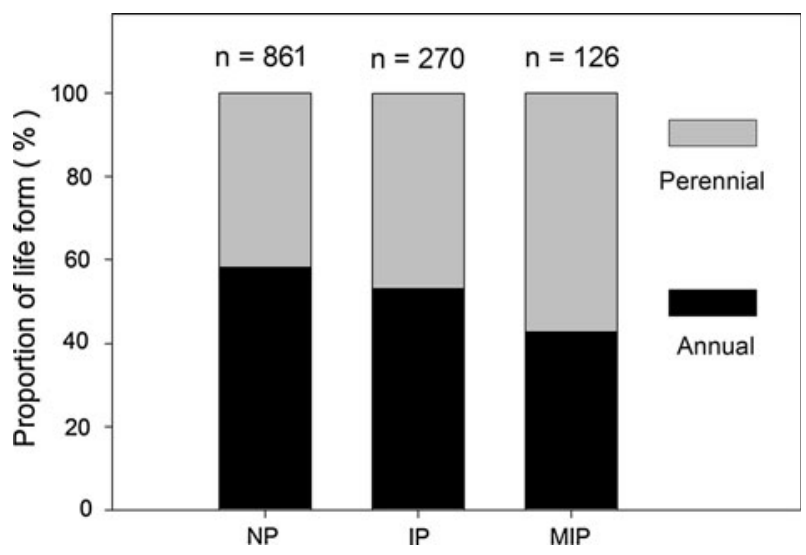

Fig. 4 Changes of proportion of life form during naturalization and invasion stages. Data of invasive plants are extracted from Weber et al. (2008), and data of major invasive plants are from Liu et al. (2006). NP naturalized plants, $I P$ invasive plants, $M I P$ major invasive plants. Annuals used here include annual or biennial herb and vein; perennials used here include perennial herb, herb/shrub, shrub, liana and tree

A total of 28 genera hold five or more naturalized plants, six of which hold ten or more; all of these are very species plant genera. The naturalized proportions of these and other genera in China were also remarkably high, for examples, $100 \%$ naturalization ratios for Alternanthera, Agave, Lolium, Mimosa, Oenothera and Opuntia, and over 50\% for Amaranthus, Ipomoea, Senna and Trifolium (Table 3). Furthermore, according to the risk assessment conducted by Feng and Zhu (2010), these genera also contained approximately one-third of the most noxious invasive plants in China, such as Alternanthera philoxeroides, Lolium temulentum, Ipomoea purpurea, and Solanum rostratum. The naturalized species belonging to these genera should be monitored carefully, and further introduction of species belonging to these genera should be minimized.

The geographical origin of naturalized species may influence their invasiveness in new areas (Wu et al. 2004a, b; Arianoutsou et al. 2010). As in most naturalized floras, naturalized plant species in China originated from all continents. These data presented here are fairly consistent with previous analyses of the geographical origins of invasive plants in China (Liu et al. 2006; Xu et al. 2006b; Wu et al. 2010a), and in neighboring regions (Corlett 1988; Enomoto 1999; Koh et al. 2000). We can speculate as to two probable reasons for such a high proportion of American species in the alien flora of China (52\%). First, this could be driven by the fact that naturalization success is increased with similarity of climate and biota: China and North America share a wide range of similar environments and related biota, which may render each region more susceptible to each other's immigrant species than species from elsewhere (Guo 1999, 2002). Second, commerce between the two regions has soared in the past few decades, which could have facilitated an upsurge in the transport of plant propagules from North America to China (Liu et al. 2006; Ding et al. 2008; Weber et al. 2008). On the other hand, China is potentially less prone to invasions by South African plants in the near further; since there is quite low exchange of trade and tourism between China and South Africa, although the climate of China is suitable for certain plants originating from South Africa (Liu et al. 2005; Thuiller et al. 2005).

The question of whether it is possible to determine a set of traits that predispose a species towards naturalization has been a central theme since the emergence of invasion ecology as a discrete field of study (Richardson and Pyšek 2006; Pyšek and Richardson 2007). Life 
form (usually separating species into annual, biennial, perennial, shrubs, and trees) of a naturalized flora are the most frequently analyzed traits (Lloret et al. 2004). It is a general pattern that the life form spectrum of the naturalized taxa is characterized by a high proportion of herbaceous taxa (Pyšek et al. 2002; Lambdon et al. 2008; Weber et al. 2008). The naturalized flora of China is similarly characterized by a prevalence of annuals and perennial herbs among the naturalized plants. The high fraction of annuals (about 60\%) in our list is likely driven by a high number of agricultural weeds. Elsewhere, annuals are often the least serious environmental weeds, suggesting that they are mainly weeds of disturbed grounds (Rejmánek and Richardson 1996; Weber 2003; Weber et al. 2008). Here, however, comparison of our data on naturalized plants to those compiled by other authors on invasive and "major" invasive plants reveals that proportions of perennial species are actually higher among invasives (Fig. 4). Our findings therefore provide new evidence that the role of life form in affecting the invasiveness of alien plants seems to be stage-specific: annuals are at an advantage during naturalization, while invasiveness seems to be associated with longerlived life forms (Pyšek et al. 2003). The perennial life cycle, which often implies vegetative propagation and clonality, might play an important role in the invasion process and success for alien species (Liu et al. 2006; Hulme et al. 2008; Milbau and Stout 2008). A recent risk assessment concurs that the most notorious invasive plants in China are those with perennial life cycles, clonal growth ability, and origin in the American continent (Huang et al. 2009). The number of naturalized trees in China was relatively low (53, Appendix S1), compared with those in many other parts of the world (Weber 1997; Pyšek et al. 2002). There were two possible reasons for this; first because the introduction history of trees in China was relatively short (Zheng and Zhang 2006), and second because the time-lags of trees between introduction and naturalization were always much longer than those of grasses or herbs (Daehler 2009). However, it should be noted that in the last three decades, over 1,000 tree species (or cultivars) have been introduced to China as ornamental plants or forestry species (Zheng and Zhang 2006), and some of these newly-introduced trees (e.g., Sonneratia apetala) have spread rapidly and invaded many natural reserves. Therefore, much attention should be paid to the potential for naturalization and invasiveness of perennial aliens in China, especially the numerous newly-introduced woody species.

Acknowledgments We thank Dr. Thomas Brooks of NatureServe for his help in improving the quality of the manuscript. We are also grateful to Mr. Hua-Xuan Zhang and Dr. Lu-Jun Yu of Sun Yat-sen University for their assistance with data collection. This study was supported financially by the Hongda Zhang Scientific Research Fund of Sun Yat-sen University and the National Natural Science Foundation of China (30970548).

Open Access This article is distributed under the terms of the Creative Commons Attribution Noncommercial License which permits any noncommercial use, distribution, and reproduction in any medium, provided the original author(s) and source are credited.

\section{References}

Arianoutsou M, Bazos I, Delipetrou P, Kokkoris Y (2010) The alien flora of Greece: taxonomy, life traits and habitat preferences. Biol Invasion 12:3525-3549

Corlett R (1988) The naturalized flora of Singapore. J Biogeogr 15:657-663

Corlett R (1992) The naturalized flora of Hong Kong: a comparison with Singapore. J Biogeogr 19:421-430

Daehler CC (1998) The taxonomic distribution of invasive angiosperm plants: ecological insights and comparison to agricultural weeds. Biol Conserv 84:167-180 
Daehler CC (2009) Short lag times for invasive tropical plants: evidence from experimental plantings in Hawai'i. PLoS One 4:e4462

Ding JQ, Wang R (1998) Invasive alien species and their impact on biodiversity in China. In: The Compilation Group of China's Biodiversity (ed) China's biodiversity: a country study. China Environmental Science Press, Beijing, pp 58-63

Ding JQ, Mack RN, Lu P, Ren MX, Huang HW (2008) China's booming economy is sparking and accelerating biological invasions. Bioscience 58:317-324

Douglas H, Dang PT, Gill BD, Huber J, Mason PG et al (2009) The importance of taxonomy in responses to invasive alien species. Biodiversity 10:92-99

Elton CS (1958) The ecology of invasions by animals and plants, 2nd edn. Methuen, London

Enomoto T (1999) Naturalized weeds from foreign countries into Japan. In: Yano E, Matsuo K, Shiyomi M, Andow DA (eds) Biological invasions of ecosystem by pests and beneficial organisms. National Institute of Agro-Environmental Science, Tsukuba, pp 1-14

Feng J, Zhu Y (2010) Alien invasive plants in China: risk assessment and spatial patterns. Biodivers Conserv 19:3489-3497

Guo QF (1999) Ecological comparisons between eastern Asia and North America: historical and geographical perspectives. J Biogeogr 26:199-206

Guo QF (2002) Perspectives on trans-Pacific biological invasions. Acta Phytoecol Sin 26:724-730

Heywood VH (1989) Patterns, extents, and modes of invasions by terrestrial plants. In: Drake JA Mooney HA, di Castri F, Groves RH, Kruger FJ, Rejmánek M, Williamson M (eds). Biological invasions: a global perspective, scope 37. Wiley, New York, pp 31-60

Heywood VH (1993) Flowering plants of the world. Oxford University Press, New York

Hickman JC (1993) The Jepson manual: higher plants of California. University of California Press, Berkeley

$\mathrm{Hu}$ L, Li MG, Li Z (2010) Geographical and environmental gradients of lianas and vines in China. Glob Ecol Biogeogr 19:554-561

Huang QQ, Wu JM, Bai YY, Zhou L, Wang GX (2009) Identifying the most noxious invasive plants in China: role of geographical origin, life form and means of introduction. Biodivers Conserv 18:305-316

Hulme PE, Brundu G, Camarda IPD, Lambdon P et al (2008) Assessing the risks to Mediterranean islands ecosystems from alien plant introductions. In: Tokarska-Guzik B, Brock JH, Brundu G, Child L, Daehler CC et al (eds) Plant invasions: human perception, ecological impacts and management. Backhuys Publishers, Leiden, pp 39-56

Khuroo AA, Rashid I, Reshi Z, Dar GH, Wafai BA (2007) The alien flora of Kashmir Himalaya. Biol Invasion 9:269-292

Koh KS, Na JG, Suh MH, Kil JH, Ku YB et al (2000) The effects of alien plants on ecosystem and their management (I). The Plant Taxonomic Society of Korea. National Institute of Environmental Research, Seoul, p 95

Lambdon PW, Pysek P, Basnou C, Hejda M, Arianoutsou M et al (2008) Alien flora of Europe: species diversity, temporal trends, geographical patterns and research needs. Preslia 80:101-149

Li ZY, Xie Y (2002) Invasive alien species in China. China Forestry Publishing House, Beijing

Lin W, Zhou GF, Cheng XY, Xu RM (2007) Fast economic development accelerates biological invasions in China. PLoS One 2:e1208

Liu J, Liang SC, Liu FH, Wang RQ, Dong M (2005) Invasive alien plant species in China: regional distribution patterns. Divers Distrib 11:341-347

Liu J, Dong M, Miao SL, Li ZY, Song MH et al (2006) Invasive alien plants in China: role of clonality and geographical origin. Biol Invasion 8:1461-1470

Lloret F, Medail F, Brundu G, Hulme PE (2004) Local and regional abundance of exotic plant species on Mediterranean islands: Are species traits important? Glob Ecol Biogeogr 13:37-45

Lonsdale WM (1999) Global patterns of plant invasions and the concept of invasibility. Ecology $80: 1522-1536$

Mabberley DJ (1997) The plant-book. A portable dictionary of the vascular plants. Cambridge University Press, Cambridge

Meyerson LA, Mooney HA (2007) Invasive alien species in an era of globalization. Front Ecol Environ 5:199-208

Milbau A, Stout JC (2008) Factors associated with alien plants transitioning from casual, to naturalized, to invasive. Conserv Biol 22:308-317

Morton JK, Venn JM (1990) A checklist of the flora of Ontario vascular plants. Univ. Waterloo Biol. Ser. no. 34 , pp 1-218

Ng S, Corlett R (2002) The bad biodiversity: alien plant species in Hong Kong. Biodivers Sci 10:109-118

Pimentel D, Lach L, Zuniga R, Morrison D (2000) Environmental and economic costs of nonindigenous species in the United States. Bioscience 50:53-65 
Pyšek P (1998) Is there a taxonomic pattern to plant invasions? Oikos 82:282-294

Pyšek P, Richardson DM (2007) Traits associated with invasiveness in alien plants: where do we stand? In: Nentwig W (ed) Biological invasions. Springer, Berlin, pp 97-125

Pyšek P, Sádlo J, Mandák B (2002) Catalogue of alien plants of the Czech Republic. Preslia 74:97-186

Pyšek P, Sádlo J, Mandák B, Jarosik V (2003) Czech alien flora and the historical pattern of its formation: What came first to Central Europe? Oecologia 135:122-130

Pyšek P, Richardson DM, Rejmánek M, Webster GL, Williamson M et al (2004) Alien plants in checklists and floras: towards better communication between taxonomists and ecologists. Taxon 53:131-143

Qiang S, Cao X (2000) Survey and analysis of exotic weeds in China. J Plant Resour Environ 9:31-38

Rabitsch W, Essl F (2006) Biological invasions in Austria: patterns and case studies. Biol Invasion 8:295-308

Rejmánek M, Richardson DM (1996) What attributes make some plant species more invasive? Ecology 77:1655-1661

Richardson DM, Pyšek P (2006) Plant invasions: merging the concepts of species invasiveness and community invasibility. Progr Phys Geogr 30:409-431

Richardson DM, Pyšek P, Rejmánek M, Barbour MG, Panetta FD et al (2000) Naturalization and invasion of alien plants: concepts and definitions. Divers Distrib 6:93-107

Thuiller W, Richardson DM, Pyšek P, Midgley GF, Hughes GO et al (2005) Niche-based modeling as a tool for predicting the risk of alien plant invasions at a global scale. Glob Change Biol 11:2234-2250

Vilà M, Meggaro Y, Weber E (1999) Preliminary analysis of the naturalized flora of northern Africa. Orsis 14:9-20

Villaseñor JL, Espinosa-Garcia FJ (2004) The alien flowering plants of Mexico. Divers Distrib 10:113-123

Wang FG, Xing FW, Ye HG, Chen XY, Tang GG et al (2004) Preliminarily study on invasive alien species in Macau. Acta Sci Nat Univ Sun Yat Sen 43:105-110

Weber EF (1997) The alien flora of Europe: a taxonomic and biogeographic review. J Veg Sci 8:565-572

Weber E (2003) Invasive plant species of the world. A reference guide to environmental weeds. CABI, Wallingford

Weber E, Li B (2008) Plant invasions in China: What is to be expected in the wake of economic development? Bioscience 58:437-444

Weber E, Sun SG, Li B (2008) Invasive alien plants in China: diversity and ecological insights. Biol Invasion 10:1411-1429

Wu SH, Hsieh CF, Chaw SM, Rejmánek M (2004a) Plant invasions in Taiwan: insights from the flora of casual and naturalized alien species. Divers Distrib 10:349-362

Wu SH, Hsieh CF, Rejmánek M (2004b) Catalogue of the naturalized flora of Taiwan. Taiwania 49:16-31

Wu T, Meng C, Dai J, Zhu Y (2006) Exotic plants in Shangdong Province. J Shangdong Norm Univ (Nat Sci Ed) 21:105-109

Wu SH, Sun HT, Teng YC, Rejmánek M, Chaw SM et al (2010a) Patterns of plant invasions in China: taxonomic, biogeographic, climatic approaches and anthropogenic effects. Biol Invasion 12:2179-2206

Wu SH, Yang TYA, Teng YC, Chang CY, Yang KC et al (2010b) Insights of the latest naturalized flora of Taiwan: change in the past eight years. Taiwania 55:139-159

Xiang YC, Peng SL, Zhou HC, Cai XA (2002) The impacts of non-native species on biodiversity and its control. Guihaia 22:425-432

Xie Y, Li ZY, Gregg WP, Dianmo L (2001) Invasive species in China-an overview. Biodivers Conserv 10:1317-1341

Xu HG, Ding H, Li MY, Qiang S, Guo JY et al (2006a) The distribution and economic losses of alien species invasion to China. Biol Invasion 8:1495-1500

Xu HG, Qiang S, Han ZM, Guo JY, Huang ZG et al (2006b) The status and causes of alien species invasion in China. Biodivers Conserv 15:2893-2904

Yan YH, He ZX, Gong Q, Chen HF, Xing FW (2007) The alien plant species in Guangzhou, China. Guihaia 27:570-575

Zerbe S, Choi IK, Kowarik I (2004) Characteristics and habits of non-native plant species in the city of Chonju, southern Korea. Ecol Res 19:91-98

Zheng YQ, Zhang CH (2006) Current status and progress of studies in biological invasion of exotic trees. Sci Silv Sin 42:115-122 